\title{
Health alterations in nursing students after a year from admission to the undergraduate course*
}

\author{
Alterações de saúde em estudantes de enfermagem um ano \\ depois do ingresso no curso de graduação \\ Alteraciones de salud en estudiantes de enfermería un año \\ después del ingreso en la carrera universitaria
}

How to cite this article:

Silva RM, Costa ALS, Mussi FC, Lopes VC, Batista KM, Santos OP. Health alterations in nursing students after a year from admission to the undergraduate course. Rev Esc Enferm USP. 2019;53:e03450. DOI: http://dx.doi.org/10.1590/S1980-220X2018008103450

\section{Rodrigo Marques da Silva ${ }^{1}$ \\ Ana Lúcia Siqueira Costa ${ }^{2}$ \\ Fernanda Carneiro Mussi ${ }^{3}$ \\ Victor Cauê Lopes ${ }^{4}$ \\ Karla de Melo Batista ${ }^{5}$ \\ Osmar Pereira dos Santos ${ }^{6}$}

* Extracted from the thesis: "Alterações de saúde, resiliência e qualidade de vida de discentes de graduação em enfermagem no primeiro ano letivo", Universidade de São Paulo, 2017.

${ }^{1}$ Faculdade de Ciências e Educação Sena Aires, Brasília, DF, Brazil.

${ }^{2}$ Universidade de São Paulo, Escola de Enfermagem, Departamento de Enfermagem Médico Cirúrgica, São Paulo, SP, Brazil.

${ }^{3}$ Universidade Federal da Bahia, Salvador, BA, Brazil.

${ }^{4}$ Associação Juinense de Ensino Superior. Juína, MT, Brazil.

${ }^{5}$ Universidade Federal do Espírito Santo, Vitória, ES, Brazil.

${ }^{6}$ Faculdade União de Goyazes,

Trindade, GO, Brazil.

\begin{abstract}
Objective: To identify health alterations in nursing students after a year from admission to a nursing undergraduate course. Method: A longitudinal prospective study with a quantitative approach was carried out in 2016 with first-year nursing students from two universities in the state of São Paulo. The following instruments were applied at the beginning and the end of the first school year: an instrument for Assessment of Stress in Nursing Students, the Center for Epidemiologic Studies Depression Scale, and the Pittsburgh Sleep Quality Index. The ANOVA test for mixed models was used for analysis. Results: The sample was made up of 117 students in March and 100 students in December. A significant increase in stress in all dimensions of the instrument, a reduction in the duration and subjective quality of sleep, and an increase in general stress and depressive symptoms were observed. Conclusion: The nursing academic environment presents the potential for students to become ill. Institutions should rethink their curricular elements, promote resilience, and create spaces to promote students' health.
\end{abstract}

\section{DESCRIPTORS}

Students, Nursing; Education, Nursing; Stress, Psychological; Resilience, Psychological; Mental Health. 


\section{INTRODUCTION}

Within the period students are enrolled in undergraduate nursing courses, they experience the nursing reality and demands from healthcare services. In addition, students need to meet curricular requirements and manage their time to maintain social and family relationships. In this context, they experience situations inherent to the nursing profession and academic context, which may be evaluated as stressors ${ }^{(1)}$. At the national level, potential stressors in the academic environment are associated with situations regarding tests, extracurricular tasks, and the transition from pre-college to the academic environment ${ }^{(2)}$. International studies also highlight, as stressors, academic activities experienced during the first 12 months of college; traumatic death experiences; responsibility with the care of others; demands regarding performance and interpersonal relationships; and feeling of unpreparedness to carry out tasks in internship areas and practical classes ${ }^{(3-4)}$. Furthermore, reports of difficulty in managing time to meet academic demands and balance personal and social activities were observed as frequent stressors among students ${ }^{(2,4)}$.

Based on the overview identified by several studies regarding stressors in the academic environment, it is possible to reflect on their effects for the health of nursing students, which includes higher stress levels, increased depressive symptoms, and reduced quality of sleep, with an impact on quality of life. In this respect, studies in the area have emphasized different distress predictors in nursing students, such as the university environment ${ }^{(5)}$, load of activities, tasks associated with undergraduate courses, lack of knowledge and professional skills, relationship with professors, and clinical environment ${ }^{(6)}$.

Stress is described as any stimulus coming from the external or internal environment that demands or exceeds sources of adaptation of an individual or social system ${ }^{(7)}$. In the present study, this phenomenon will be approached in the psychological and emotional context, that is, as a subjective sense commonly experienced in the conjunction between stress feelings and health alterations. The incidence of stress among nursing students has already been observed in several studies $^{(2,8-9)}$. Among them, one study carried out with 130 nursing students in southern Brazil showed that $9.23 \%$ of them presented a high stress level and $67.69 \%$ presented a moderate stress level ${ }^{(9)}$. One study carried out with 129 nursing students in the state of São Paulo identified that $24.6 \%$ of the second-year students and $25 \%$ of the third-year students presented a high stress level ${ }^{(8)}$.

Depressive symptoms may lead to suffering and significant social and occupational harm, and, upon clinical evaluation, may configure a depressive disorder, which is the fourth greatest disabling cause in the world ${ }^{(10)}$. This symptomatology is evaluated with an emphasis on the following emotional and behavioral components: a depressed mood, guilt and uselessness feelings, a sense of lack of support and despair, psychomotor retardation, loss of appetite, and sleep disorders ${ }^{(11)}$. In one study carried out with 729 students from a university in the USA, $16.5 \%$ presented these symptoms, $30.6 \%$ presented moderate depression, and $23.2 \%$ presented severe or moderately severe depression ${ }^{(12)}$. In one study carried out with high-school students in China, 6.4\% presented these symptoms ${ }^{(13)}$. The association between stress and symptoms of depression was statistically significant in one study carried out with approximately 5,000 university students from Canada, showing that higher stress levels resulted in higher depression symptom rates ${ }^{(14)}$. In addition, some researchers describe symptoms of depression as poor sleep quality predictors. This same association was observed in one study carried out with 3,186 students from China, in which students with symptoms of depression were 2.47 times more likely to present sleep quality alterations ${ }^{(13)}$.

Similarly to stress and symptoms of depression, quality of sleep may negatively affect nursing students' health. This phenomenon is of utmost importance among healthcare professionals and students, as they will be future professionals, because the lack of restorative sleep contributes significantly to errors in health care ${ }^{(15)}$. Poor sleep quality was observed in $60 \%$ of the students from university courses analyzed in a study carried out in Chicago ${ }^{(16)}$. Regarding the consequences of poor sleep quality, one study carried out with 1,074 university students from the state of Texas showed that the group that reported insomnia presented lower sleep quality scores, as well as higher symptoms of depression and anxiety scores ${ }^{(17)}$. One study carried out in India with 750 nursing students showed that students with better sleep quality presented less insomnia and depression, with daily capacity to study longer ${ }^{(15)}$. In the Brazilian context, one study carried out with 49 university students from a private institution in the state of São Paulo showed a significant and negative correlation between quality of sleep and depression symptom scores ${ }^{(18)}$. Consequently, it may be concluded that neuroendocrine stress manifestations lead to lower sleep quality and depression symptomatology in students, in addition to poor sleep quality being associated with the increase in symptoms of depression, which impact on quality of life.

Therefore, nursing students, when entering higher education institutions, are exposed to several stressors, which may lead to health alterations such as higher stress levels, an increase in symptoms of depression, and a reduction in quality of sleep. However, despite several studies presented, the longitudinal analysis of health after entering nursing courses is still limited, especially regarding quality of sleep, which is a phenomenon that may lead to physical, cognitive, and emotional alterations, in addition to a reduction in academic performance.

In this respect, the objective of the present study was to identify alterations (stress, symptoms of depression, and quality of sleep) in the health of nursing students one year from the admission to courses. The following assumptions were defined: alterations in the health of nursing after one year from the admission to courses, with an increase in stress levels and symptoms of depression, and a reduction in quality of sleep.

\section{METHOD}

\section{StUdY DESIGN}

This was a prospective longitudinal study with a quantitative approach, carried out with undergraduate nursing 
students of one federal and one state university in the state of São Paulo.

\section{Population}

The study population was made up of all first-year nursing students from both institutions, which voluntarily accepted to participate in the study by signing a free and informed consent form.

Students aged 18 years or older and regularly enrolled in the first semester of the first year of each institution were included. Those who, during data collection, were unable to undertake all classes of the semester due to failing in the previous semester were excluded.

\section{Data Collection}

The data were collected by means of a study protocol applied in two stages: at the beginning of classes (March 2016) and the end of the second semester (December 2016). This protocol was made up of the following instruments: the instrument for Assessment of Stress in Nursing Students (ASNS), the Center for Epidemiologic Studies Depression Scale (CESD), and the Pittsburgh Sleep Quality Index (PSQI).

The ASNS was proposed by Costa and Polak in 2009 ${ }^{(2)}$, and is made up of 30 items grouped into the following six domains: Performance of practical activities (items 4, 5, 7, 9, 12, and 21); Professional communication (items 6, 8, 16, and 20); Time management (items 3, 18, 23, 26, and 30); Environment (items 11, 22, 24, and 29); Professional education (items 1, 15, 17, 19, 25, and 27); and Theoretical activity (items $2,10,13,14$, and 28). The items are presented in a 4-point Likert scale with the following characteristics: 0 - "I do not experience the situation"; 1 - "I do not feel stressed with the situation"; 2 - "I do not feel much stressed with the situation"; and 3 - "I feel very stressed with the situation" ${ }^{(2)}$. Risk quartiles were used to identify stress levels in the ASNS domains, as defined by the instrument's authors ${ }^{(2)}$. In order to observe the overall stress level of students, the sum of the scores attributed to the 30 items of the instrument was calculated with a comparison between the stress scores obtained at the beginning and the end of the first year of the course. In the validation process, the following alpha values were found for the ASNS domains: 0.806 (Performance of practical activities), 0.768 (Professional communication), 0.717 (Time management), 0866 (Environment), 0.772 (Professional education), and 0.720 (Theoretical activity) ${ }^{(2)}$.

The CES-D was semantically validated into Portuguese by Silveira and Jorge in $1998^{(19)}$ and applied in Brazilian university students by Filho and Teixeira in $2011^{(10)}$. The objective of this instrument is to evaluate depression symptomatology experienced in the week prior to the instrument's application. It consists of 20 scalar items on mood, somatic symptoms, interactions with others, and motor functioning. These are distributed into the following four subscales: Depressed affect (items 3, 6, 9, 10, 14, 17, and 18), Interpersonal problems (items 15 and 19), Positive affect (items 4, 8, 12, and 16), and Somatic symptoms and retarded activities (items $1,2,5,7,11,13$, and 20). These items are presented in a 4 -point Likert scale, being $0=$ Rarely or none of the time (less than one day), 1 = Some or a little of the time (1-2 days), 2 = Occasionally or a moderate amount of time (3-4 days), and $3=$ Most or all of the time (5-7 days) ${ }^{(10)}$. The following Cronbach's alpha values were obtained in the instrument's validation process for Brazilian university students: 0.89 for the 20 items; 0.86 for the Depressed affect subscale; 0.70 for Interpersonal problems; 0.65 for Positive affect; and 0.75 for Somatic symptoms and retarded activities ${ }^{(10)}$.

Once validated into the Brazilian reality, the PSQI was adapted and used in Brazilian university students from different places ${ }^{(20-21)}$. This instrument consists of ten questions with the following characteristics: 1-4-open-ended questions and 5-10 - semi-closed questions. These questions are distributed into the following seven components: Subjective sleep quality (question 6); Sleep latency (questions 2 and 5a); Sleep duration (question 4); Habitual sleep efficiency (questions 1, 3, and 4); Sleep disturbances (questions $5 \mathrm{~b}$ up to $5 \mathrm{j}$ ); Use of sleeping medications (question 7); Daytime dysfunction over the last month (questions 8 and 9$)^{(20)}$. Question 10 is optional and will not be applied in this study, because it requires the presence of a roommate for analysis ${ }^{(20)}$. The overall score is achieved by the sum of each component's score, which value ranges from zero to three. Therefore, the possible maximum value is 21 points, and, the higher the score, the worse the quality of sleep. In the two data collection stages, these instruments were personally delivered in the classrooms, after authorization and direct scheduling with professors of the classes to be conducted in the nursing courses. A date for their collection was scheduled in the classrooms, with the assistance of class representatives and students who offered help in this process. In addition, to increase adherence to the study, results were individually sent by e-mail to the students who participated in the study.

\section{Data ANALYSIS AND TREATMENT}

For data organization and analysis, a database in the Microsoft Excel software (Office 2010) was created and the statistical R Package 3.3.0 was used. The instruments were analyzed, as previously mentioned, according to the analyses described by the instruments' authors. Qualitative variables were presented in absolute values ( $\mathrm{n}$ ) and percentages $(\mathrm{n} \%)$, and quantitative variables were presented in the following descriptive measures: minimum and maximum values, mean, and standard deviation. The ANOVA test, a model with mixed effects to compare the means obtained over time for each phenomenon, was used to evaluate alterations in stress, symptoms of depression, and quality of sleep scores in nursing students. The results were considered statistically significant when $\mathrm{p}<0.05$. Cronbach's alpha was used to analyze the reliability of the instruments applied. In the evaluation of health alterations, the academic environment of the nursing undergraduate course was considered the predictor variable, and the other phenomena under analysis (stress, symptoms of depression, and quality of sleep) were considered outcome variables. 


\section{ETHICAL ASPECTS}

The research project was submitted and approved by the research ethics committee of the state public institution under protocol no. 1.363.890. Later, an amendment was submitted to the committee to include the federal public institution as the data collection setting, with approval under protocol no. 1.400.103. In addition, this project was submitted to the research service of the state institution to be reviewed with regard to its viability and merit, being approved by the responsible committee. According to the guidelines and regulatory standards for research involving human beings (Resolution
466/12 of the National Health Council), a free and informed consent form was sent to the participants together with the instruments, which was signed by the participants in two copies (one for the participant and the other for the researcher), agreeing to voluntarily participate in the study.

\section{RESULTS}

A total of 117 students answered the research protocol in March, and 100 in December. Students' detailed exclusion flow according to eligibility criteria is presented below (Figure 1).

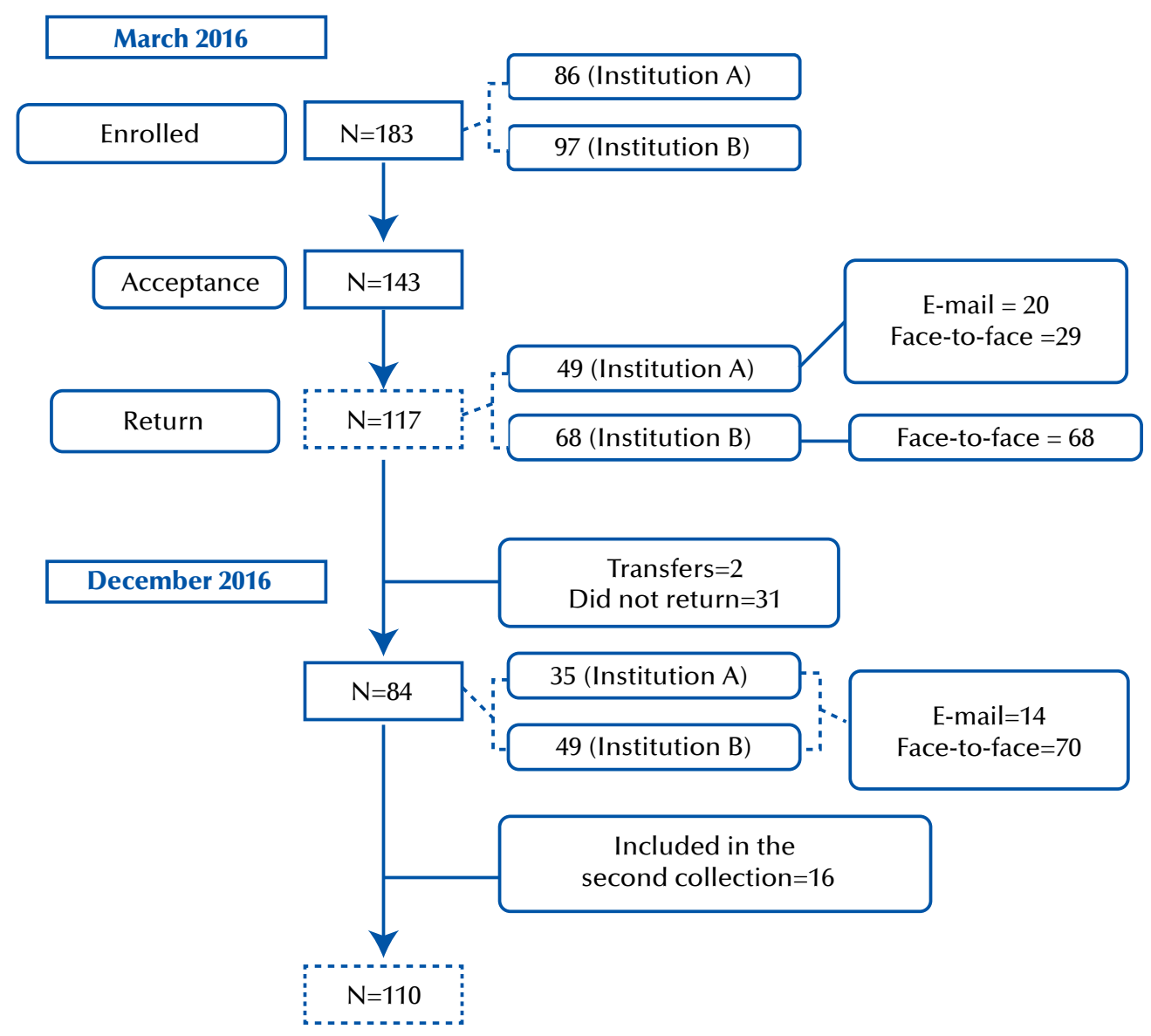

Figure 1 - Exclusion flow of the participants in the study.

Figure 1 shows that in March, of the 183 students enrolled in the two institutions studied, 143 agreed to participate in the study; however, only 117 returned the instruments filled in. In December, of the 117 students included in the study, 33 were excluded, totaling 84 students in both months. However, 16 students who did not participate in the collection stage in March were included in December. Therefore, the sample of December was made up of 100 nursing students. Table 1 presents the sociodemographic characteristics of the nursing students in both months analyzed.
Table 1 shows a prevalence of female, young (approximately 20 years of age), and single students without children, who live in the city of São Paulo in their own apartments or houses with their families, on which they are financially dependent for their monthly maintenance. In spite of performing leisure activities, not smoking, and not making use of medications to sleep, there was a prevalence of students who did not practice sports, who used medications to inhibit sleep, and who consumed alcohol monthly or weekly. Figure 2 presents the stress variation according to each domain of the ASNS throughout 2016. 
Table 1 - Sociodemographic characteristics of the nursing students in March and December 2016 - São Paulo, SP, Brazil, 2016.

\begin{tabular}{|c|c|c|}
\hline \multirow{2}{*}{$\begin{array}{l}\text { Sociodemographic variables* } \\
\text { n (\%) or Mean (SD) }\end{array}$} & March $2016(n=117)$ & December $2016(n=100)$ \\
\hline & n $(\%)$ or Mean $(\mathrm{SD})$ & n (\%) or Mean (SD) \\
\hline Gender (female) & $99(84.6 \%)$ & $88(88.0 \%)$ \\
\hline Age & $20.73(4.4)$ & $20.90(5.1)$ \\
\hline Marital status (single/without a partner) & $98(83.8 \%)$ & $78(78 \%)$ \\
\hline Children (no) & $112(95.7 \%)$ & $98(98 \%)$ \\
\hline Living in São Paulo (yes) & $100(85.5 \%)$ & $83(83 \%)$ \\
\hline Living with (a family) & $94(80.3 \%)$ & $81(81 \%)$ \\
\hline Living in (their own apartment/house) & $77(65.8 \%)$ & $65(65 \%)$ \\
\hline High school (private school) & $60(51.3 \%)$ & $52.0(52 \%)$ \\
\hline Sports (no) & $77(65.8 \%)$ & $76(76 \%)$ \\
\hline Leisure (yes) & $71(60.7 \%)$ & $61(61 \%)$ \\
\hline Source of income (family resources) & $81(69.2 \%)$ & $66(66 \%)$ \\
\hline Medications to inhibit sleep (yes) & $67(57.3 \%)$ & $52(52 \%)$ \\
\hline Medications to sleep (no) & $104(88.9 \%)$ & $85(85 \%)$ \\
\hline Smoker (no - never smoked) & $107(91.5 \%)$ & $88(88 \%)$ \\
\hline Alcohol consumption (yes) & $74(63.2 \%)$ & $65(65 \%)$ \\
\hline \multicolumn{3}{|l|}{ Frequency of alcohol consumption } \\
\hline Monthly & $38(32.5 \%)$ & $36(36 \%)$ \\
\hline Weekly & $31(26.5 \%)$ & $26(26 \%)$ \\
\hline
\end{tabular}

*Prevalent categories for each variable.

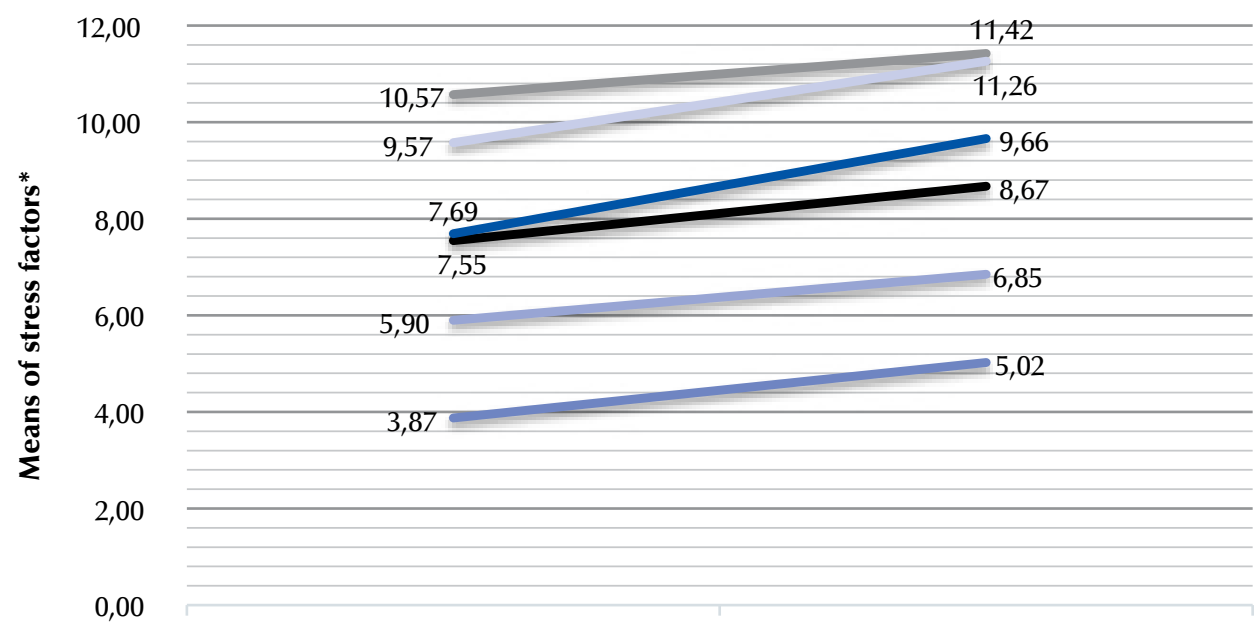

March 2016

Performance of practical activities*

Time management*

Professional education**
December 2016

Professional communication*

Environment*

Theoretical activities**

*p $<0.05 ; * * \mathrm{p}<0.001 ;{ }^{* * *}$ ANOVA for mixed models.

Figure 2-Variation of the stress level of each domain of the ASNS in nursing students after the first school year in the undergraduate course. 
Between March and December 2016, a statistically significant increase in stress levels was observed in all domains of the ASNS: Performance of practical activities ( $\mathrm{p}=0.038)$; Time management $(\mathrm{p}=0.014)$; Professional communication ( $\mathrm{p}=0.007)$; Environment ( $\mathrm{p}=0.003)$; Professional education $(p<0.001)$; and Theoretical activities $(p<0.001)$. Table 2 shows the variation in symptoms of depression and quality of sleep scores of each component in the period analyzed in nursing students.

A statistically significant increase in scores of the component "Somatic symptoms and retarded activities" (difficulties in engaging and maintaining daily activities) was observed. Because the PSQI has a reverse scale, the data above show a reduction in subjective sleep quality and sleep duration. The analysis of means shows that, in March, students slept 6 hours per night $(\mathrm{SD}=1.42)$ on average, and in December, this mean of sleep dropped to 5.41 hours $(\mathrm{SD}=1.27)$. Figure 3 presents variations in stress levels, symptoms of depression, and quality of sleep (general) in nursing students.

In the figure above, of the three constructs analyzed, a statistically significant increase in general stress levels and symptoms of depression was observed in nursing students throughout the school year of 2016. The increase in scores of symptoms of depression implies an increase in the frequency that students experienced these symptoms in the period analyzed. For stress, the score represents an increase in stress intensity experienced throughout the school year.

Table 2 - Score variation of each component of the CES-D and the PSQI in nursing students - São Paulo, SP, Brazil, 2016.

\begin{tabular}{lccc}
\hline \multirow{2}{*}{ Variable** } & \multicolumn{2}{c}{ Means (SD) } & p-value \\
\cline { 2 - 3 } & March & December & \\
\hline CES-D & & & \\
Depressed affect & 13.78 & 14.71 & 0.210 \\
Interpersonal problems & 3.00 & 3.48 & 0.060 \\
Positive affect & 9.36 & 9.58 & 0.336 \\
Somatic symptoms and retarded & 16.00 & 17.21 & \\
activities & & & $0.007^{*}$ \\
\hline PSQI & & & \\
Subjective sleep quality & 1.51 & 1.81 & $0.001^{*}$ \\
Sleep latency & 1.29 & 1.36 & 0.622 \\
Sleep duration & 1.38 & 1.78 & $0.009^{*}$ \\
Habitual sleep efficiency & 0.46 & 0.38 & 0.295 \\
Sleep disturbances & 2.38 & 2.29 & 0.426 \\
Use of sleeping medications & 0.15 & 0.19 & 0.171 \\
Daytime dysfunction & 2.65 & 2.71 & 0.077 \\
\hline
\end{tabular}

*Statistically significant value $(\mathrm{p}<0.05) ;{ }^{* *}$ ANOVA for mixed models.

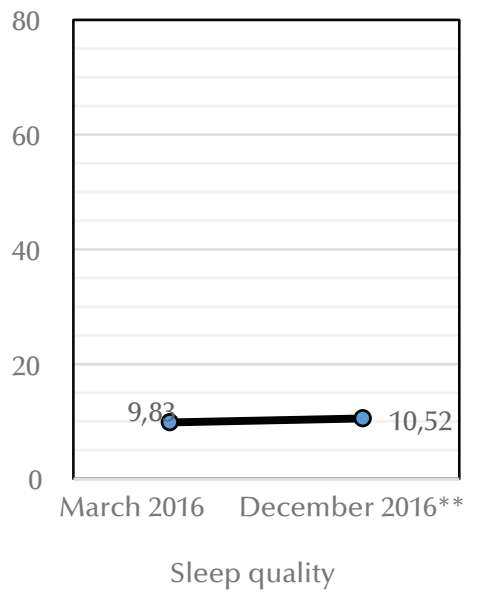

* $\mathrm{p}<0.05$; **ANOVA for mixed models.
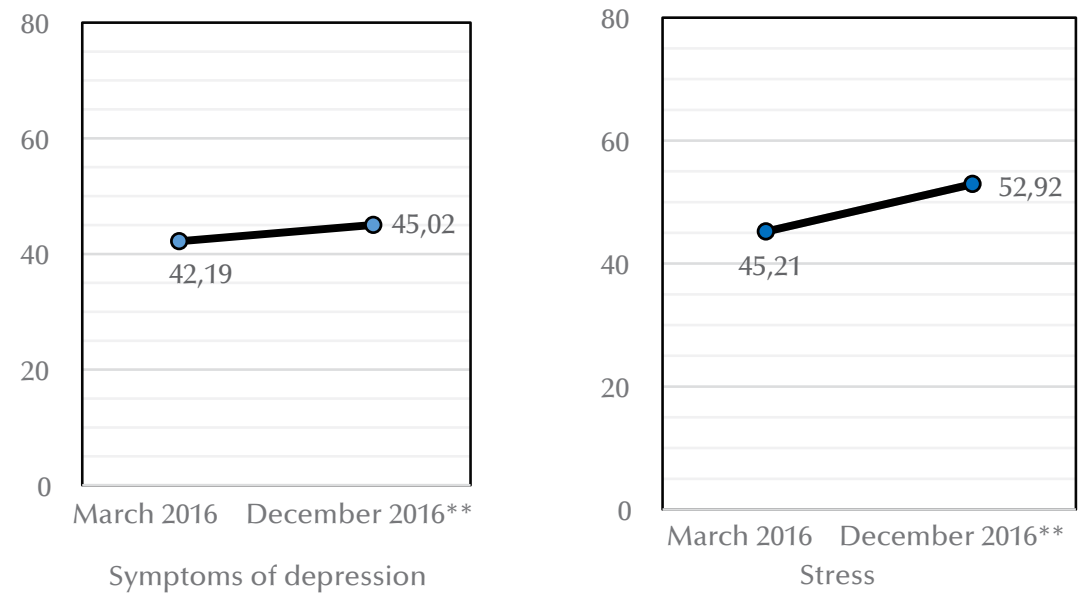

Figure 3 -Alteration in stress levels, symptoms of depression, and quality of sleep in nursing students one year after course admission.

\section{DISCUSSION}

After monitoring students for one year after course admission, a significant increase in stress levels in all domains of the ASNS was observed: Performance of practical activities, Time management, Professional communication, Environment, Professional education, and Theoretical activities. In one systematic review carried out in 2012, the following stressors were identified in firstyear nursing students, by means of different measurement instruments: admission to a university course; significant volume of activities in a short period of time; maintenance of good grades; evaluations and exams; managing of financial issues; committing errors with patients; and learning clinical procedures ${ }^{(22)}$. In one longitudinal study carried out with 853 nursing students from Scotland, an increase in stress levels associated with academic overload, personal problems, interpersonal relationships, and concern with clinical aspects was observed after follow-up since their admission up to the end of the first year ${ }^{(23)}$. These stressors match the domains of the ASNS, because issues associated with evaluations, tests, and grades are described in the domain "Theoretical activities"; financial aspects and changes experienced when entering courses are approached in the domain "Environment"; "Time management" involves issues regarding difficulty in managing academic demands in order to be able to 
meet social, family, and personal needs; and concern with clinical aspects, such as procedures and patient handling, are associated with the domain "Performance of practical activities ${ }^{(2-3)}$. Therefore, previous studies with recently admitted students confirm an increase in the intensity of the stressors found in the present study throughout the first year. For this reason, researchers recommend improvements in the nursing curricula area, based on stressors evidenced in the literature, which includes considering the time required to undertake the activities proposed in order to prevent overload and use alternative types of evaluation that go beyond skills and knowledge acquisition tests ${ }^{(22)}$. The success of this type of action was corroborated by one study carried out in 2000 with nursing students enrolled in two curricular systems in Scotland (traditional and innovative), which showed that students enrolled in courses with new curriculum (focused on students and problem solving) led to lower stress levels and use of more successful confrontation strategies ${ }^{(23)}$.

Because the PSQI has a reverse scale, the increase in scores indicates a reduction in duration and subjective sleep quality among nursing students in the period evaluated. In March, students slept 6 hours per night $(\mathrm{SD}=1.42)$ on average, and in December, this mean of sleep dropped to 5.41 hours ( $\mathrm{SD}=1.27)$. After monitoring new students in an undergraduate nursing course in Campinas, a city in the state of São Paulo, researchers observed a prevalence of poor quality of sleep and a reduction in sleep duration $(\mathrm{p}=0.002)^{(24)}$. Students sleep less than the amount of time considered sufficient, that is, seven hours per night ${ }^{(25)}$, with an increase in this situation throughout the year among Brazilian students, which explains why their subjective sleep quality is evaluated as poor or very poor. An insufficient amount of sleep makes organisms unable to regulate or properly restore essential functions, such as memory, thermoregulation, energy, brain metabolism, lymphocyte levels, and cholesterol ${ }^{(26)}$. This may cause a cognitive deficit and mood alterations, greater vulnerability to illnesses, especially chronic diseases, weight gain, and a reduction in academic performance ${ }^{(27)}$. In this respect, one study carried out in Los Angeles showed that, among 535 high-school students, regardless of the daily length of study, students who were deprived of sleep to study (more than usual) had more difficulty in understanding contents taught in class and had to strive more to undertake tests or school tasks ${ }^{(28)}$. Based on the negative impact of sleep on organic and psychic functioning, it is necessary to develop and apply interventions enabling students to maintain an appropriate sleep pattern suitable to individual needs. Sleep hygiene, based on the change of dietary and behavioral habits, has stood out as a measure able to improve the subjective sleep quality of university students, and to prevent long-term outcomes, such as the increase in stress levels and symptoms of depression ${ }^{(29)}$.

In this context, the significant increase in general stress levels stands out, especially in the component "Somatic symptoms and retarded activities" (CES-D), in nursing students throughout the school year of 2016. The increase in symptoms of depression showed an increase in the frequency that students experienced these symptoms in the period analyzed, especially those associated with difficulty in engaging and maintaining daily activities (component "Somatic symptoms and retarded activities")(10). One study carried out with 187 first-year medical students in India showed an increase in stress levels from 9.19 to 12.69 , and symptoms of depression, which ranged from 14.02 to 17.78 , since their admission in the course up to the end of the year ${ }^{(30)}$. Stress negatively impacts on students' physical and mental health and may lead to Burnout Syndrome, poor quality of sleep, weight gain, absenteeism due to illness, and withdrawal from courses ${ }^{(23)}$. Therefore, in addition to the revision of the traditional curricular structure, managers of educational institutions should consider the possibility of regular evaluations of students for early identification of psychological disorders, especially those caused by the educational process ${ }^{(30)}$.

The non-detailed description of procedures and analyses of construct validity and reliability of the instruments used, and the lack of longitudinal studies with nursing students stand out as limitations of this research, which hindered the comparison of the findings of the present research with other studies involving students in the same area.

\section{CONCLUSION}

After one year of the admission to the courses, an increase in stress levels, a reduction in subjective sleep quality, and an increase in the intensity of symptoms of depression (overall score and component "Somatic symptoms and retarded activities") were observed; however, with no significant alterations in quality of sleep scores (general). These findings partially confirm the initial hypothesis of this study, that is, an increase in stress levels and symptoms of depression, and a reduction in quality of sleep (general).

In conclusion, the nursing educational environment presents the potential to make students ill and suffer. In this respect, educational institutions must be the focus of analysis and actions that promote a healthy educational environment within their spaces and possibilities. For this purpose, the load of theoretical activities, difficulties in managing time between academic and personal demands, in addition to limitations regarding professional communication, are stressors that may be minimized by means of institutional actions, such as revision of curricular elements.

Training programs for resilient personalities could be promoted and applied in the institutional environment, because they are able to reduce harmful stress effects, increase the quality of sleep, and reduce the intensity of symptoms of depression to which students are exposed. Finally, the possibility of creating inner spaces exclusively focused on students' demands with multidisciplinary teams for the prevention of illnesses and health promotion stands out, which is a successful experience already undertaken in some developed countries. Therefore, education with better general health and quality of life for nursing students will be possible. 
RESUMO

Objetivo: Identificar as alterações ocorridas na saúde de estudantes de enfermagem um ano depois do ingresso no curso. Método: Pesquisa longitudinal, prospectiva e quantitativa, realizada em 2016 junto a estudantes de enfermagem do primeiro ano de duas universidades de São Paulo. No início e no final do ano letivo, aplicaram-se: Instrumento para Avaliação do Estresse em Estudantes de Enfermagem, Center for Epidemiologic Studies Depression Scale e Índice de Qualidade de Sono de Pittsburgh. Para a análise, utilizou-se do teste ANOVA para modelos mistos. Resultados: Compuseram a amostra 117 estudantes em março e 100 em dezembro. Verificouse aumento significativo do estresse em todos os domínios do instrumento, redução da duração e da qualidade subjetiva do sono e aumento do estresse geral e dos sintomas depressivos. Conclusão: $\mathrm{O}$ ambiente acadêmico de enfermagem apresenta potencial para o adoecimento do estudante. Sugere-se que as instituições repensem seus elementos curriculares, promovam a resiliência e criem espaços de promoção à saúde dos estudantes.

\section{DESCRITORES}

Estudantes de Enfermagem; Educação em Enfermagem; Estresse Psicológico; Resiliência Psicológica; Saúde Mental.

\section{RESUMEN}

Objetivo: Identificar las alteraciones de salud en estudiantes de enfermería un año después del ingreso en la carrera universitaria. Método: Investigación longitudinal, prospectiva y cuantitativa, llevada a cabo en 2016 con estudiantes de enfermería del primer año de dos universidades de São Paulo. En el inicio y el fin del año lectivo, se aplicaron: Instrumento para Evaluación del Estrés en Estudiantes de Enfermería, Center for Epidemiologic Studies Depression Scale e Índice de Calidad de Sueño de Pittsburgh. Para el análisis, se utilizó la prueba ANOVA para modelos mixtos. Resultados: Compusieron la muestra 117 estudiantes en marzo y 100 en diciembre. Se verificó aumento significativo del estrés en todos los dominios del instrumento, reducción de la duración y la calidad subjetiva del sueño y aumento del estrés general y de los síntomas depresivos. Conclusión: El entorno académico de enfermería presenta potencial para que el estudiante se enferme. Se sugiere que los centros repiensen sus elementos curriculares, promuevan la resiliencia y creen espacios de promoción a la salud de los estudiantes.

\section{DESCRIPTORES}

Estudiantes de Enfermería; Educación en Enfermería; Estrés Psicológico; Resiliencia Psicológica; Salud Mental.

\section{REFERENCES}

1. Costa ALS. Estresse em discentes de enfermagem: construção dos fatores determinantes. REME Rev Min Enferm. 2007;11(4):414-9.

2. Costa ALS, Polak C. Construction and validation of an instrument for the assessment of stress among nursing students. Rev Esc Enferm USP. 2009;43(n.spe):1017-26. DOI: http://dx.doi.org/10.1590/S0080-62342009000500005

3. Bayram N, Bilgel N. The prevalence and socio-demographic correlations of depression, anxiety and stress among a group of university students. Soc Psychiatry Psychiatr Epidemiol. 2008;43(8):667-72.

4. Montgomery P, Mossey S, Killam L. Views of second year nursing students on impediments to safety in the clinical setting: Q-methodology. J Nurs Educ Pract. 2013;3(8):1-12.

5. Bublitz S, Freitas EO, Kirchhof RS, Lopes LFD, Guido LA. Estressores entre acadêmicos de enfermagem e uma universidade pública. Rev Enferm UERJ. 2012;20(n.esp.2):739-45.

6. Labrague LJ. Stress, stressors, and stress responses of student nurses in a government nursing school. Health Sci J. 2013;7(4):424-35.

7. Lazarus RS, Folkman S. Stress, appraisal, and coping. New York: Springer; 1984.

8. Basso Musso L, Vargas BA, Torres MB, Canto MJM, Meléndez CG, Balloqui MFK. Fatores derivados dos laboratórios intra-hospitalares que provocam estresse nos estudantes de enfermagem. Rev Latino Am Enfermagem. 2008;16(5):805-11.

9. Silva RM, Goulart CT, Lopes LFD, Costa ALS, Guido LA. Avaliação de estresse em estudantes de enfermagem: proposta de padronização da análise. In: Rossi AM, Meurs JA, Perrewé PL, organizadores. Stress e qualidade de vida no trabalho: melhorando a saúde e bem-estar dos funcionários. Porto Alegre: Atlas; 2013. p. 55-67.

10. Hauck Filho N, Teixeira MAP. A estrutura fatorial da Escala CES-D em estudantes universitários brasileiros. Aval Psicol. 2011;10(1):91-7.

11. Matos ACS, Oliveira IR. Terapia cognitivo-comportamental da depressão: relato de caso. Rev Ciênc Med Biol. 2013;12(n.spe):512-9.

12. Garlow SJ, Rosenberg J, Moore JD, Haas AP, Koestner B, Hendin H, et al. Depression, desperation, and suicidal ideation in college students: results from the American Foundation for Suicide Prevention College Screening Project at Emory University. Depress Anxiety. 2008;25(6):482-8.

13. Guo L, Deng J, He Y, Deng X, Huang J, Huang G, et al. Prevalence and correlates of sleep disturbance and depressive symptoms among Chinese adolescents: a cross-sectional survey study. BMJ Open. 2014;4(7):1-9.

14. Sawatzky RG, Ratner PA, Richardson CG, Washburn C, Sudmant W, Mirwaldt P. Stress and depression in students: the mediating role of stress management self-efficacy. Nurs Res. 2012;61(1):13-21.

15. Menon B, Karishma HP, Mamatha IV. Sleep quality and health complaints among nursing students. Ann Indian Acad Neurol. 2015;18(3):3634.

16. Lund HG, Reider BD, Whiting AB, Prichard JR. Sleep patterns and predictors of disturbed sleep in a large population of college students. J Adolesc Health. 2010;46(2):124-32.

17. Taylor DJ1, Bramoweth AD, Grieser EA, Tatum JI, Roane BM. Epidemiology of insomnia in college students: relationship with mental health, quality of life, and substance use difficulties. Behav Ther. 2013;44(3):339-48.

18. Coelho AT, Lorenzini LM, Suda EY, Rossini S, Reimão R. Sleep quality, depression and anxiety in college students of last semesters in health area's courses. Neurobiologia. 2010;73(1):35-9. 
19. Silveira DX, Jorge MR. Escala de rastreamento populacional para depressão CES-D em populações clínicas e não clínicas de adolescentes e adultos jovens. In: Gorestain C, Andrade LHSG, Zuarde AW, editores. Escalas de avaliação clínica em psiquiatria e farmacologia. São Paulo: Lemos; 2000. p.125-34.

20. Benavente SBT, Silva RM, Higashi AB, Guido LA, Costa ALS. Influence of stress factors and socio-demographic characteristics on the sleep quality of nursing students. Rev Esc Enferm USP. 2014;48(3):514-20. DOI: http://dx.doi.org/10.1590/S0080-623420140000300018

21. Ferreira CMG, Kluthcovsky ACGC, Dornelles CF, Stumpf MAM, Menezes T, Cordeiro G. Qualidade do sono em estudantes de medicina de uma universidade do Sul do Brasil. Conexão Ci. 2017;12(1):78-85.

22. Pulido-Martos M, Augusto-Landa JM, Lopez-Zafra E. Sources of stress in nursing students: a systematic review of quantitative studies. Int Nurs Rev. 2012;59(1):15-25.

23. Jones MC, Johnston W. Is the introduction of a student-centred, problem-based curriculum associated with improvements in student nurse well-being and performance? An observational study of effect. Int J Nurs Stud. 2006;43(8):941-52.

24. Furlani R, Ceolim MF. Padrões de sono de estudantes ingressantes na Graduação em Enfermagem. Rev Bras Enferm. 2005;58(3):320-4.

25. Peltzer K, Pengpid S1. Sleep duration and health correlates among university students in 26 countries. Psychol Health Med. 2016;21(2):20820.

26. Winston TN. Handbook on burnout and sleep deprivation. New York: NOVA; 2015.

27. Araújo MFM, Lima ACS, Alencar AMPG, Araújo TM, Fragoaso LVC, Damasceno MMC. Sleep quality assessment in college students from Fortaleza-CE. Texto Contexto Enferm. 2013;22(2):352-60. DOI: http://dx.doi.org/10.1590/S0104-07072013000200011

28. Gillen-O'Neel C, Huynh VW, Fuligni AJ. To study or to sleep? The academic costs of extra studying at the expense of sleep. Child Dev. 2013;84(1):133-42.

29. Yazdi Z, Loukzadeh Z, Moghaddam P, Jalilolghadr S. Sleep hygiene practices and their relation to sleep quality in medical students of Qazvin University of Medical Sciences. J Caring Sci. 2016;5(2):153-60.

30. Goel AD, Akarte SV, Agrawal SP, Yadav V. Longitudinal assessment of depression, stress, and burnout in medical students. J Neurosci Rural Pract. 2016;7(4):493-8. 